\title{
ACCURACY AND SENSITIVITY OF A METHOD OF JUMP DETECTION, EVALUATED BY SIMULATED TIME SERIES
}

\author{
Yavor CHAPANOV $^{1)}$ *, Cyril RON $^{2)}$ and Jan VONDRÁK ${ }^{2)}$ \\ ${ }^{1)}$ National Institute of Geophysics, Geodesy and Geography, Bulgarian Academy of Sciences, \\ Acad. G. Bonchev Str. Bl.3, Sofia 1113, Bulgaria \\ ${ }^{2)}$ Astronomical Institute, Czech Academy of Sciences, Bočni II 1401, 14100 Prague 4, Czech Republic
}

*Corresponding author's e-mail: yavor.chapanov@gmail.com

\section{ARTICLE INFO}

Article history:

Received 20 July 2016

Accepted 23 August 2016

Available online 11 October 2016

Keywords:

Time series

Data jump detection

\begin{abstract}
The modern knowledge in the field of many geosciences is based on permanent observations during the last decades. These data are represented by various long time series of the observed natural changes. They consist mainly of quasi harmonic oscillations with variable phases and amplitudes and small irregular variations, containing abrupt changes due to certain natural sources of impulse excitations. These variations may be due to various geophysical impulses and in some cases to the inaccuracy of data collection from the many different instruments spread on all over the world. The natural sources of the observed quasi impulse variations with duration from seconds to days are earthquakes, hurricanes and tornadoes, geomagnetic jerks, landslides, solar eruptions etc. The data jumps in the long time series may be due to the inaccuracy of classical instrumental techniques or to the changes of the networks arising from the adding or removing the observational stations and replacement of the instruments. The direct determination of the data jumps is a difficult task, because the jumps are very small in relation to the amplitudes of the seasonal, interannual, short and long periodic terms of the observed variations. A new high-sensitive method of small jumps determination in long time series has been formulated recently (Chapanov et al., 2014). This method detects any sudden changes of the mean data value and of the linear trend, whose magnitude is significantly less than the level of the random noise. The accuracy and sensitivity of this method is evaluated by simulated time series of polar motion, VLBI pole offset, GPS and climatic data. The accuracy of the method is determined by the differences between the initial and estimated values of data jumps. The sensitivity of the method is determined as a level of jumps, detectable for any specific data collection.
\end{abstract}

\section{INTRODUCTION}

The modern knowledge uses time series of many years' permanent observations. The data may contain some small systematic deviations due to instrument and station changes. There are many methods for the jump detection in a time series used in multiple scientific contexts, as geophysics, genetics, image processing and others. More information on the methods and their comparison is available in Rodionov (2005). We have used a method that is a modified CUSUM method based on cummulative sums. We have already applied the method to the determination of systematic deviations from the mean values in (Chapanov et al., 2008a, 2008b, 2013, 2014; Gambis et al., 2011; Ron et al., 2014) by means of linear trends in integrated time series. This approach is used here in a method of data jumps detection and moreover for detection of the changes in trend by means of finding parabolic and/or linear trends in the integrated time series.

\section{METHOD OF IMPULSE DETECTION}

The method of data jumps determination consists of five steps as follows;

1. Removal of global linear trend. Usually, all time series contain a small or large linear trend. Its level depends on linear velocity of the measured object, or some fictive residuals of preprocessed data. This first step is necessary to obtain restricted variation of integrated data in the second step.

2. Time series integration. The time series are integrated numerically by the well known trapezoidal rule. Let us consider a function $f$ of the argument $x$, discretized into $N+1$ equidistant points $f\left(x_{i}\right), i=1,2, \ldots$, $N+1$. Let the first argument $x_{1}=a$, and last argument $x_{N+1}=b$. Then the grid spacing is $h=(b-a) / N$ and the trapezoidal approximation to the integral is 


$$
\begin{aligned}
& \int_{a}^{b} f(x) d x \approx \frac{h}{2} \sum_{k=1}^{N}\left[f\left(x_{k+1}\right)+f\left(x_{k}\right)\right] \\
& \quad=\frac{b-a}{2 N}\left[f\left(x_{1}\right)+2 f\left(x_{2}\right)+\cdots 2 f\left(x_{N}\right)+f\left(x_{N+1}\right)\right]
\end{aligned}
$$

When the grid spacing is non-uniform, we can use the formula

$$
\int_{a}^{b} f(x) d x \approx \frac{1}{2} \sum_{k=1}^{N}\left(x_{k+1}-x_{k}\right)\left[f\left(x_{k+1}\right)+f\left(x_{k}\right)\right] .
$$

To obtain an integral of a given time series $f\left(t_{i}\right), i=1$, $2, \ldots, N+1$ it is necessary to integrate $N$ times the function $f$ with boundaries $a=t_{1}$ and $b=t_{i}, i=2, \ldots$, $N+1$. The amplitudes of integrated periodic components are reciprocal to their frequencies, so the high-frequency noise results in amplitudes significantly smaller than the original data, while the low-frequency signals increase their amplitudes in integrated time series. These properties of time series integration of selective reduction/amplification of noise/signal amplitudes make the described method extremely sensitive to very small changes of observed data.

3. Separation of data parts with piecewise linear or parabolic trends. Any small jump of the original data is expressed by breaking lines in the integrated time series. The parts with linear trends of integrated data correspond to the constant mean behavior of the original data, while the parabolic trends express certain linear trend of the original data.

4. Epochs of data jumps determination. The epochs of the ends of piecewise linear or parabolic trends in integrated time series correspond to the epochs of data jumps and trend changes in the original time series.

5. Data jump and trend change calculation. Let us consider two neighboring data parts $I_{k}$ and $I_{k+1}$ from the integrated time series, each one containing data with different piecewise linear or parabolic trends. The corresponding data from the original time series are denoted by $O_{k}$ and $O_{k+1}$, with mean values $M_{k}$ and
$M_{k+1}$ and values $L_{k}=l_{k}+v_{k} t$, where $t$ is the time, $v_{k}$ is a trend and $L_{k+1}=l_{k+1}+v_{k+1} t$. Let us denote the epochs of the ends of $O_{k}$ by $T_{k-1}$ and $T_{k}$ and the ends of $O_{k+1}$ by $T_{k}$ and $T_{k+1}$. Then the data jump in the moment $T_{k}$ is $J\left(T_{k}\right)=J_{k}=M_{k+1}-M_{k}$ and the trend change is $V\left(T_{k}\right)=V_{k}=v_{k+1}-v_{k}$. Note that the linear trend in integrated time series corresponds to zero linear trend in the original data.

\section{MODELS OF SIMULATED OBSERVATIONS}

For better evaluating the sensitivity of the method of jump and trend change detection we need to generate simulated observations of various observed events taking into consideration their basic characteristics of amplitudes and frequencies.

\subsection{MODELS OF PERIODIC OSCILLATIONS OF POLAR MOTION AND LATITUDE VARIATIONS.}

The periodic oscillations of the polar motion consist of two main cycles - annual and Chandler with period of about 1.18 a, so the polar motion is almost circular with maximal diameter of about 20 meters. The modern determination of the polar motion is highly precise and its time series contains low level of random noise. The latitude variations are dominated by the polar motion, presented by polar motion projection onto the corresponding meridian plane. The long time series of latitude variations observed by optical astrometry instruments in the last century have the level of noise relatively high of about $0.1-0.2 "$.

For simplicity's sake we will use onward only xcomponent of polar motion or horizontal GPS coordinates to study their modeled jumps. The second component of polar motion exposes similar noise and seasonal variations and we can disregard it in the study. The model of simulated time series of polar motion includes Chandler and seasonal oscillations, lunar tides and their second and third harmonics and is shown in Table 1. The x-component of polar motion is calculated by formula (3).

$$
x\left(t_{i}\right)=\sum_{n=1}^{4} \sum_{k=1}^{3} A_{n k} \sin \left(\frac{2 k \pi}{p_{n}} t_{i}+\psi_{n k}\right) .
$$

Table 1 Amplitudes and phases of periodic oscillations in the model of polar motion.

\begin{tabular}{lccc}
\hline Period $P_{n}$ & Harmonics & Amplitude $A_{n}$ & Phase $\psi_{n}$ \\
\hline Chandler & 1 & $0^{\prime \prime} .300$ & $0^{\circ} .0$ \\
$\mathrm{p}_{1}=1.18 \mathrm{a}$ & 2 & .020 & 10.0 \\
& 3 & .010 & 20.0 \\
\hline Seasonal & 1 & .100 & 30.0 \\
$\mathrm{p}_{2}=1 \mathrm{a}$ & 2 & .020 & 40.0 \\
& 3 & .010 & 50.0 \\
\hline Synodic Moon period & 1 & .020 & 60.0 \\
$\mathrm{p}_{3}=29.53 / 365.25 \mathrm{a}$ & 2 & .010 & 70.0 \\
& 3 & .005 & 80.0 \\
\hline Sidereal Moon period & 1 & .010 & 90.0 \\
$\mathrm{p}_{4}=27.32 / 365.25 \mathrm{a}$ & 2 & .010 & 100.0 \\
& 3 & .005 & 110.0 \\
\hline
\end{tabular}




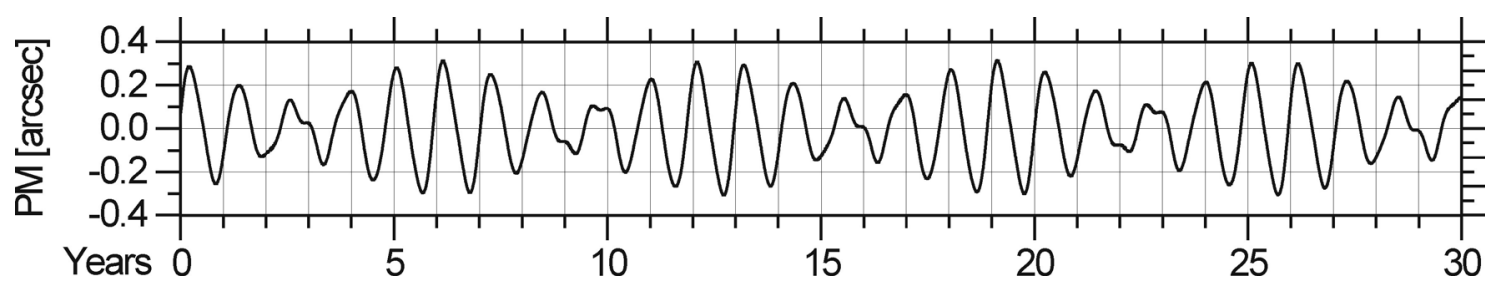

Fig. 1 Simulated time series of $\mathrm{x}$-component of polar motion.

The resulting 30-year time series of the model of the x-component of polar motion is shown in Figure 1. The latitude variations in the zero meridian are simulated by the same time series of polar motion plus a model of normally distributed random errors $\mathrm{N}(0$, 0.1 as), based on Forsythe, Malcolm and Moler algorithm (Forsythe et al., 1977). The error distribution of astronomical observations is rather different from the normal distribution, due to different instruments, observers and climatic conditions. The observational errors with a small dispersion form a "hat" above the normal fit and cause a kurtosis effect, while the errors of less accurate observations are modeled by $7 \%$ evenly distributed outliers whose magnitude is between $2.5 \sigma$ and $4 \sigma$. The "hat" is modeled by replacement of $6 \%$ of normally distributed numbers with evenly distributed numbers from interval ( -0.06 as, 0.06 as). The error model of astronomical observations is shown in Figure 2, and this model will help to determine data jumps due to outliers and observational errors. The final model of observational errors has a new value of the standard 0.14 as, so the added outliers stay hidden inside the confidence interval. The simulated time series of latitude variations are presented in Figure 3, where the latitude variations are between -1.0 as and +1.0 as while, the polar motion variations are spread between -0.3 as and +0.3 as. These two time series will help to determine the properties of the method of jump detection in the case of smooth data variations, like polar motion, and the influence of significant level of observational pseudo normally distributed random errors.

In practice, beside the normally distributed random errors, the observed data contain a lot of highfrequency pseudo periodic signals, which provide the so called "colored noise" in the time series. The effect of the high-frequency observational noise on the

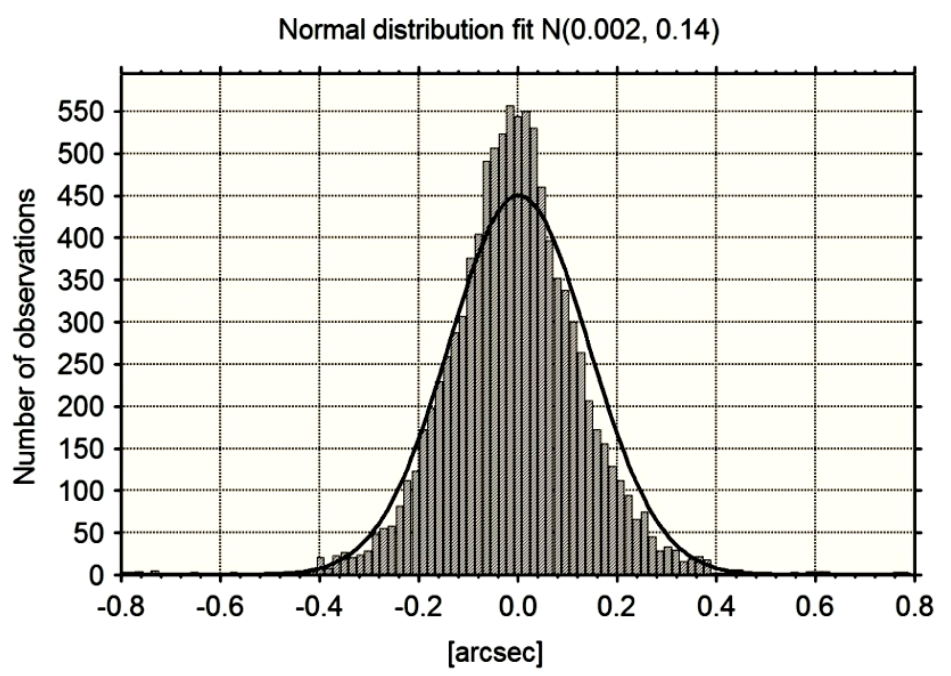

Fig. 2 Distribution of errors according to the model of random errors of astrometric observations.

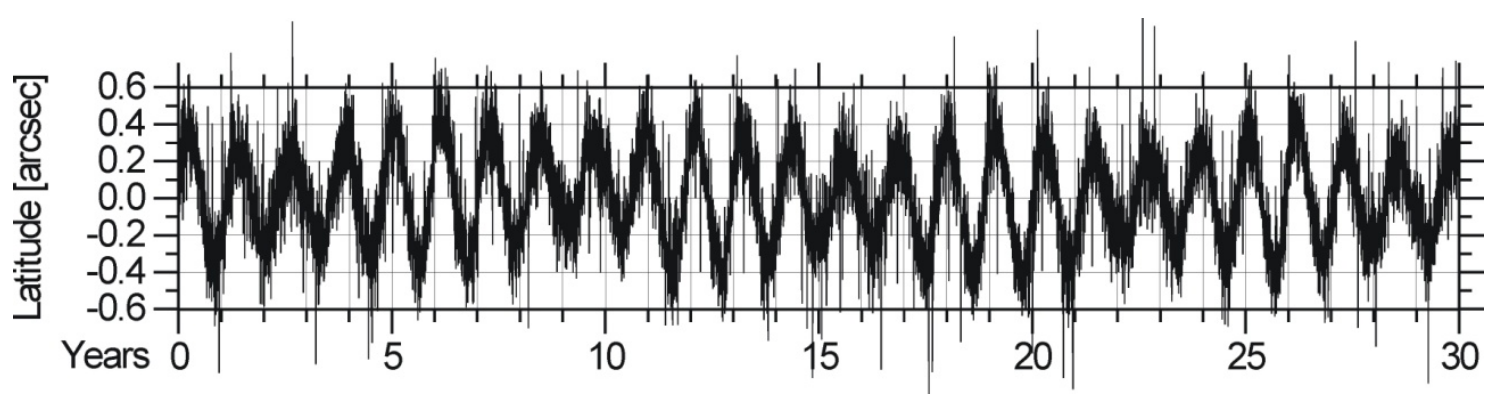

Fig. 3 Simulated time series of latitude variations. 

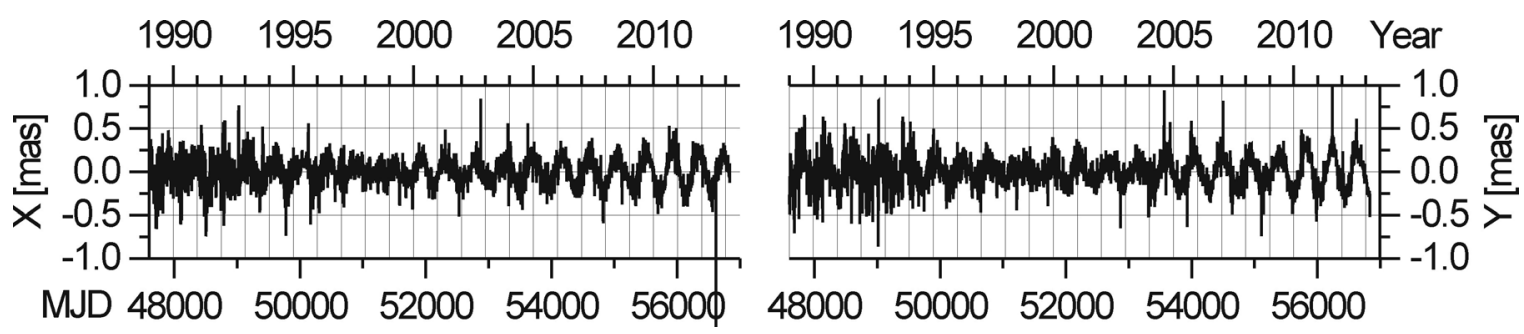

Fig. 4 High-frequency variations of celestial pole offset variations with periods below 462d, extracted from IVS data.

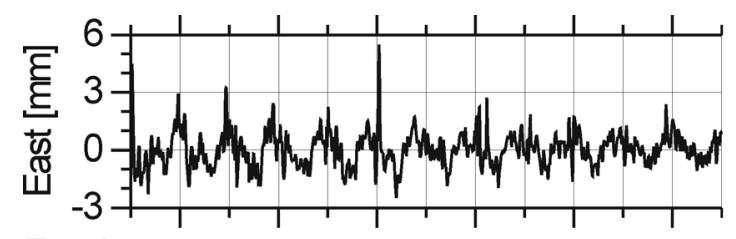

Epoch 199820002002200420062008

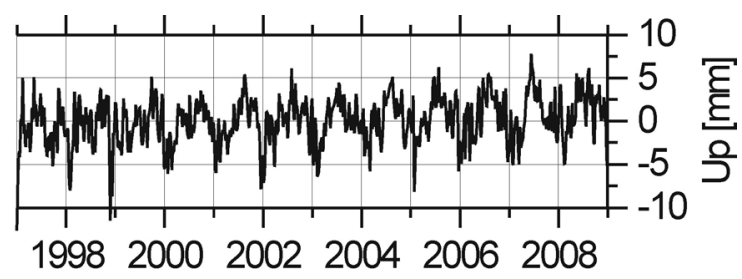

Fig. 5 High-frequency variations of GPS coordinates of station Wettzell in East and Up direction.
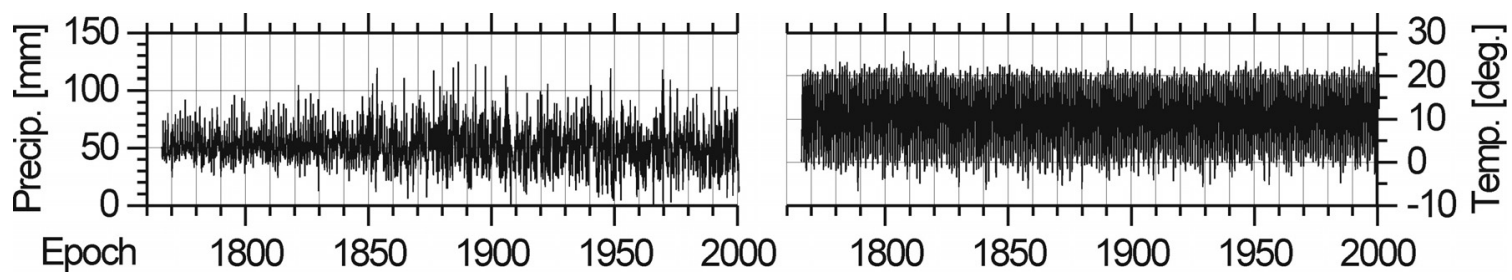

Fig. 6 Variations of precipitation and temperature over Balkan Peninsula with periods below 7 years.

properties of the method of jump detection is evaluated by means of the models of VLBI, GPS, and climatic variations, whose high-frequency oscillations are derived from the real data.

\subsection{MODELS OF HIGH-FREQUENCY OSCILLATIONS IN VLBI, GPS, AND CLIMATIC DATA}

The high-frequency oscillations with seasonal and shorter periods in VLBI, GPS, and climatic data are extracted from the real measurements by the method of Partial Fourier Approximation (PFA), whose coefficients are derived by the Least-Squares method (LS). This method is given by

$F(t)=f_{0}+f_{1}\left(t-t_{0}\right)+\sum_{k=1}^{n} a_{k} \sin \frac{2 \pi k\left(t-t_{0}\right)}{t_{e}-t_{b}}+b_{k} \cos \frac{2 \pi k\left(t-t_{0}\right)}{t_{e}-t_{b}}$,

where $f_{0}, f_{1}, a_{k}$ and $b_{k}$ are unknown coefficients, $t_{0}, t_{b}$ and $t_{e}$ are the mean, first and last data epochs, respectively, and $n$ is the harmonics number. So the expression (4) covers all oscillations from the band $2 \pi n /\left(t_{e}-t_{b}\right)$ and $2 \pi /\left(t_{e}-t_{b}\right)$. The harmonics number $n$ is chosen smaller than the number of sampled data $f_{i}$ in order to apply LS estimation of Fourier coefficients. The period of the first harmonic in (4) depends on the observational time span in case of classic Fourier approximation, but here we decrease its value so that the method estimates the whole set of desired frequencies. This method allows a flexible separation of the harmonic oscillations into different frequency bands by the formula
$B(t)=\sum_{k=m_{1}}^{m_{2}} a_{k} \sin \omega_{k}\left(t-t_{0}\right)+b_{k} \cos \omega_{k}\left(t-t_{0}\right)$,

where $m_{1}$ and $m_{2}$ are the first and last used harmonics, and the desired frequencies $\omega_{k}=\frac{2 \pi k}{t_{e}-t_{b}}$ are limited by the bandwidth

$\frac{2 \pi m_{1}}{t_{e}-t_{b}} \leq \omega_{k} \leq \frac{2 \pi m_{2}}{t_{e}-t_{b}}$.

The method of PFA allows data reconstruction in time domain by formula (5) with the desired frequency bandwidth. Doing this for VLBI, GPS, and climatic real data, we shall determine their intrinsic high-frequency variations. The VLBI data are represented by time series of celestial pole offset for the period 1989-2013. The high-frequency variations of the celestial pole offset are determined by excluding the first 23 harmonics of the PFA with periods above 462 days (Fig. 4). The high-frequency GPS coordinates variations are determined by excluding the first 12 harmonics of the PFA of Wettzell data with periods above 1 year (Fig. 5). The climate data (precipitation and temperature over Balkan Peninsula) are represented by relatively long time series, covering 235-year time span. These data are determined from the gridded European data (Casty et al., 2005, 2007). Their high-frequency variations with periods below 7.3a do not affect the small data jumps, and they are extracted by excluding the first 32 harmonics of the PFA (Fig. 6). 
(a)
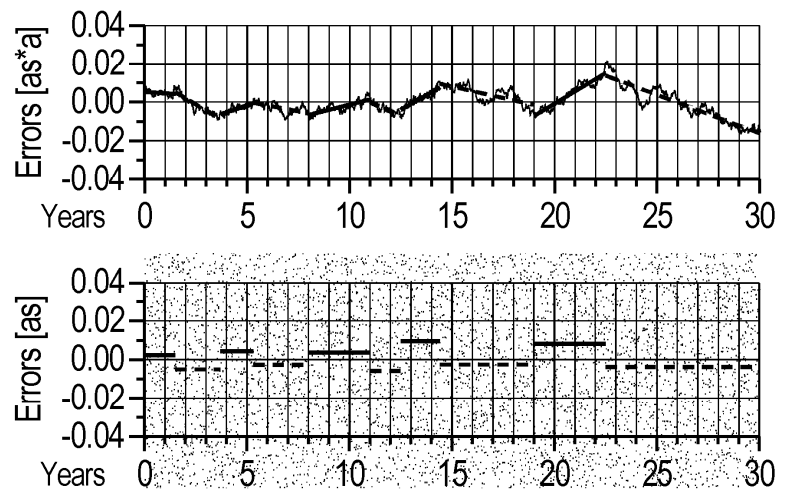

(b)
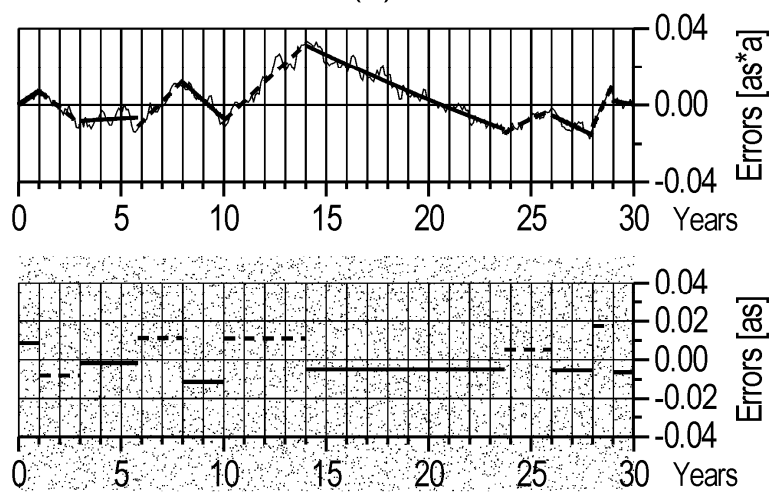

Fig. 7 Integrated time series of normally distributed random errors (a) and normally distributed random errors plus outliers (b) (upper graphs) and determined jumps.

\section{ACCURACY AND SENSITIVITY OF THE METHOD OF IMPULSE DETECTION \\ 4.1. DATA JUMPS DUE TO RANDOM NOISE AND OUTLIERS.}

The normally distributed random errors and outliers in observations also produce data jumps, whose magnitudes are examined by the model of pseudo normally distributed random errors described in the section 3.1 above. The integrated time series of normally distributed random errors and observational errors with significant outliers are shown in Figure 7. The normally distributed random errors produce several data jumps smaller than 0.01 as (Fig. 7 a). The integrated time series of the model of real observational errors with added outliers and kurtosis effect show different set of data jumps with magnitudes of about 0.02 as that are twice larger than that of normally distributed ones (Fig. 7 b). These jumps are relatively small with magnitudes smaller than $5 \%$ of maximum errors. The shortest time interval between the sign interchange of the jumps in Figure 7 is between 1.5 and 3 years, so the trend variations shorter than 5 years can be affected in the case of high level of random noise and outliers. The trend variations longer than 5 years are affected less by the outliers and random noise due to average of several data parts with the sign interchange.

\subsection{SIMULATED JUMPS OF POLAR MOTION AND LATITUDE VARIATIONS.}

In Chapanov et al. (2014), we detected jumps in the polar motion approximately every 6 years during the periods of minimal amplitude of the beat oscillations between the annual and Chandler components, when the energy of the polar motion oscillations is minimal, too. The model of simulated jumps of the polar motion and latitude variations consists of 4 jumps in the periods of minimal beating. The first 3 years of data have no jump. The adopted values of the jumps are collected in Table 2.
Table 2 Data jumps and changes in trend of the models of polar motion and latitude variations.

\begin{tabular}{ccc}
\hline $\begin{array}{c}\text { Time } \\
\text { [years] }\end{array}$ & $\begin{array}{c}\text { Data jumps } \\
\text { [mas] }\end{array}$ & $\begin{array}{c}\text { change in trend } \\
\text { [mas/a] }\end{array}$ \\
\hline $3.0-11.0$ & +50 & +10 \\
$11.0-16.0$ & 0 & 0 \\
$16.0-22.5$ & -20 & 0 \\
$22.5-30.0$ & 0 & -5 \\
\hline
\end{tabular}

The integrated time series of polar motion and latitude variations after removing the global trend, are shown in Figure 8. The determined values of the jumps by means of the original data are given in Tables 3 and 4 . The jump epochs are determined with errors less than half a year. The first 3-year part should have the zero mean value, but it results in the value 10 mas for the polar motion and 66 mas for the latitude variations. These results are consequences of the fact that the 3-year data do not cover full 6-year segment of the annual- Chandler beating period. The residuals of polar motion data jumps are between 1 mas and 13 mas, while the residuals of latitude variations are slightly higher - between 6 mas and 20 mas (Tables 3,4). The residuals of changes in trend are below 3mas/a and there are no false results. The sensitivity of the method of jump detection is then 13 mas for data jumps of polar motion, because the maximum false determination and maximum residual have the same value. The sensitivity of the method for data jumps of latitude variations is between 12 mas and 20 mas (the maximum false estimates and maximum residuals of data jumps). The sensitivity of the detection changes in trend is about 3 mas for both polar motion and latitude variations.

\subsection{SIMULATED JUMPS OF CELESTIAL POLE OFFSET.}

The adopted values of jumps of the celestial pole offset are shown in Table 5. The time intervals between the jumps are within the range of 2-7 years. 

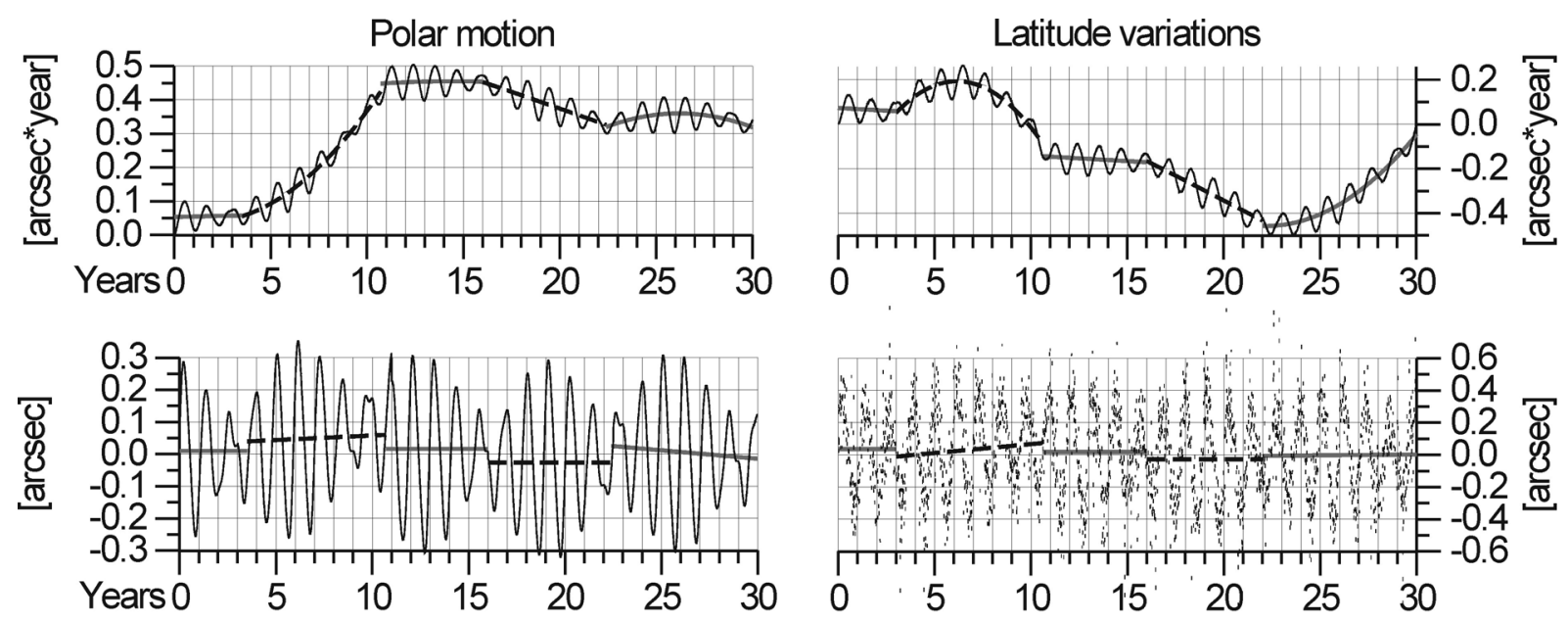

Fig. 8 Integrated time series of polar motion and latitude variations (upper graphs) and determined jumps.

Table 3 Estimated jumps of the polar motion.

\begin{tabular}{|c|c|c|c|c|c|}
\hline $\begin{array}{l}\text { Time } \\
\text { [years] }\end{array}$ & $\begin{array}{c}\text { Error } \\
\text { [years] }\end{array}$ & $\begin{array}{l}\text { Data j. } \\
\text { [mas] }\end{array}$ & $\begin{array}{l}\text { Residual } \\
\text { [mas] }\end{array}$ & $\begin{array}{c}\text { change in trend } \\
{[\mathrm{mas} / \mathrm{a}]}\end{array}$ & $\begin{array}{c}\text { Residual } \\
{[\mathrm{mas} / \mathrm{a}]}\end{array}$ \\
\hline $0.0-3.5$ & $0.0 ; 0.5$ & +10 & 10 & 0 & - \\
\hline $3.5-10.7$ & $0.5 ; \quad 0.3$ & +49 & 1 & +7 & 3 \\
\hline $10.7-16.0$ & $0.3 ; \quad 0.0$ & +13 & 13 & 0 & - \\
\hline $16.0-22.4$ & $0.0 ; \quad 0.1$ & -27 & 7 & 0 & - \\
\hline $22.4-30.0$ & $0.1 ; 0.0$ & +5 & 5 & -5.2 & 0.2 \\
\hline
\end{tabular}

Table 4 Estimated jumps of latitude variations.

\begin{tabular}{|c|c|c|c|c|c|}
\hline $\begin{array}{c}\text { Time } \\
\text { [years] }\end{array}$ & $\begin{array}{c}\text { Errors } \\
\text { [years] }\end{array}$ & $\begin{array}{l}\text { Data j. } \\
\text { [mas] }\end{array}$ & $\begin{array}{c}\text { Residuals } \\
\text { [mas] }\end{array}$ & $\begin{array}{c}\text { change in trend } \\
{[\mathrm{mas} / \mathrm{a}]}\end{array}$ & $\begin{array}{l}\text { Errors } \\
{[\mathrm{mas} / \mathrm{a}]}\end{array}$ \\
\hline $0.0-3.1$ & $0.0 ; 0.1$ & +66 & 66 & 0 & - \\
\hline $3.1-10.6$ & $0.1 ; 0.4$ & +30 & 20 & +11 & 1 \\
\hline $10.6-16.0$ & $0.4 ; \quad 0.0$ & +12 & 12 & 0 & - \\
\hline $16.0-22.0$ & $0.0 ; \quad 0.5$ & -26 & 6 & 0 & - \\
\hline $22.0-30.0$ & $0.5 ; \quad 0.0$ & +6 & 6 & -2 & 3 \\
\hline
\end{tabular}

Table 5 Data jumps and changes in trend of the model of celestial pole offset.

\begin{tabular}{ccc}
\hline Time $[\mathrm{MJD}]$ & $\begin{array}{c}\text { Data jumps } \\
{[\mathrm{mas}]}\end{array}$ & $\begin{array}{c}\text { Change in trend } \\
{[\mathrm{mas} / \mathrm{d}]}\end{array}$ \\
\hline $47600-49017$ & +80 & -0.09 \\
$49017-51100$ & -70 & 0 \\
$51100-52800$ & +20 & 0 \\
$52800-54820$ & -60 & -0.03 \\
$54820-56100$ & +10 & 0 \\
$56100-56835$ & -40 & +0.11 \\
\hline
\end{tabular}

The integrated time series of celestial pole offset and original data with the determined jumps are shown in Figure 9. The oscillations with period between $402 \mathrm{~d}$ and $462 \mathrm{~d}$ are excluded from the integrated time series by means of harmonics 20-23 of the PFA, so the resulting time series in Figure 9 have more clear breaking points, corresponding to the jumps. The residuals of the determined jump epochs are below 60 days (Tables 6,7 ), which is significantly better result in comparison with the polar motion data. Most of residuals of data jumps are below $10 \mu$ as except one that is $20 \mu$ as. The residuals of changes in trend are $0.001 \div 0.043 \mu \mathrm{as} / \mathrm{d}$, or $0.4 \div 16 \mu \mathrm{as} / \mathrm{a}$. The sensitivity of the method of impulse detection in case of celestial pole offset is about $10 \mu$ as for data jump detection and below $10 \mu$ as/a for detection of changes in trend. 

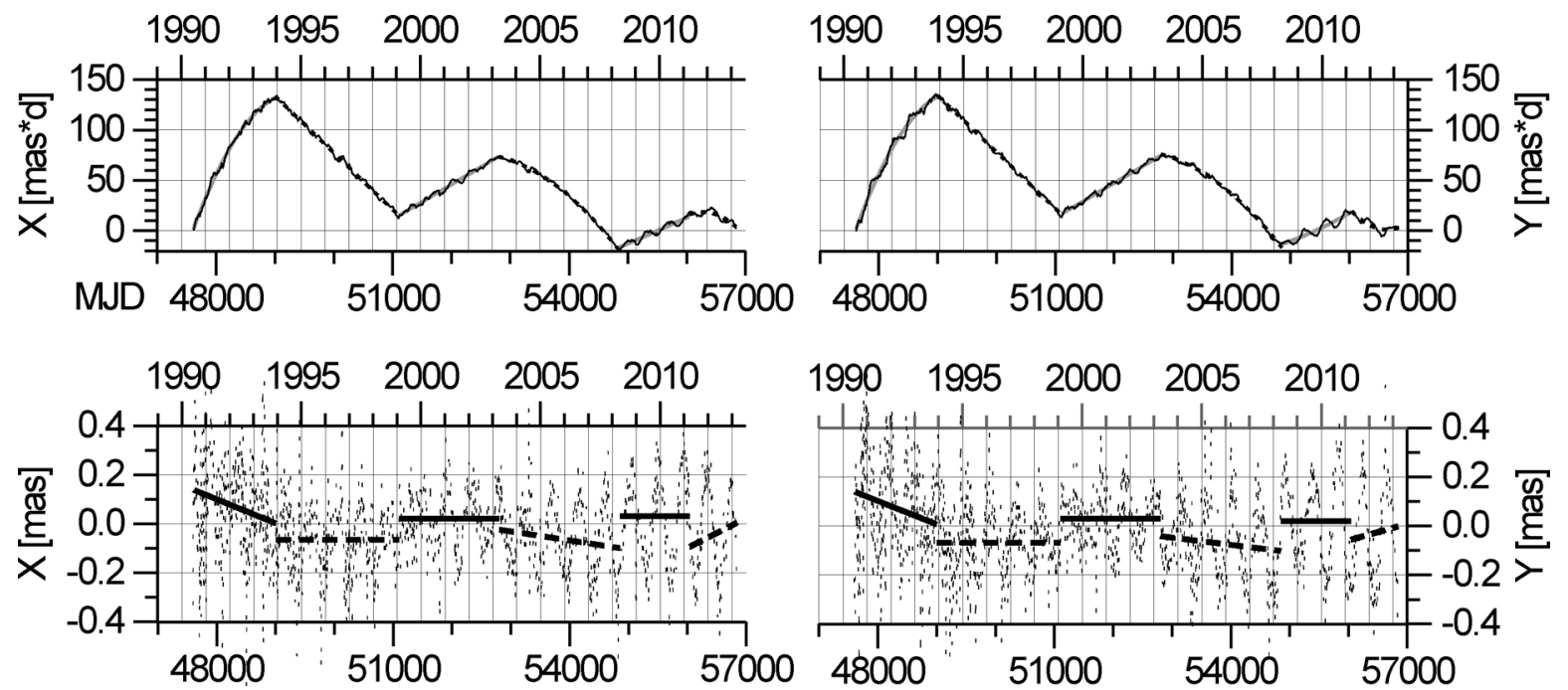

Fig. 9 Integrated time series of celestial pole offset (upper graphs) and determined jumps.

Table 6 Estimated jumps of X-coordinate of celestial pole offset.

\begin{tabular}{|c|c|c|c|c|c|}
\hline $\begin{array}{l}\text { XTime } \\
\text { [MJD] }\end{array}$ & $\begin{array}{l}\text { Residuals } \\
\text { [days] }\end{array}$ & 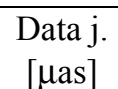 & 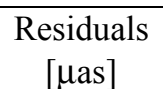 & $\begin{array}{l}\text { Trend } \\
{[\mu a s / d]}\end{array}$ & $\begin{array}{c}\text { Residuals } \\
{[\mu \mathrm{as} / \mathrm{d}]}\end{array}$ \\
\hline $47610-49000$ & $10 ; 17$ & +70 & 10 & -0.098 & 0.008 \\
\hline $49000-51100$ & $17 ; \quad 0$ & -65 & 5 & 0 & - \\
\hline $51100-52800$ & 0 & +20 & 0 & 0 & - \\
\hline $52800-54850$ & $0 ; \quad 30$ & -62 & 2 & -0.037 & 0.007 \\
\hline $54850-56040$ & $30 ; 60$ & +30 & 20 & 0 & - \\
\hline $56040-56835$ & $60 ; \quad 0$ & -45 & 5 & 0.122 & 0.011 \\
\hline
\end{tabular}

Table 7 Estimated jumps of Y-coordinate of celestial pole offset.

\begin{tabular}{cccccc}
\hline $\begin{array}{c}\text { Time } \\
{[\mathrm{MJD}]}\end{array}$ & $\begin{array}{c}\text { Residuals } \\
{[\text { days }]}\end{array}$ & $\begin{array}{c}\text { Data j. } \\
{[\mu \mathrm{as}]}\end{array}$ & $\begin{array}{c}\text { Residuals } \\
{[\mu \mathrm{as}]}\end{array}$ & $\begin{array}{c}\text { Trend } \\
{[\mu \mathrm{as} / \mathrm{d}]}\end{array}$ & $\begin{array}{c}\text { Residuals } \\
{[\mu \mathrm{as} / \mathrm{d}]}\end{array}$ \\
\hline $47610-49000$ & $10 ; \quad 17$ & +77 & 3 & -0.104 & 0.014 \\
$49000-51100$ & $17 ; \quad 0$ & -67 & 3 & 0 & - \\
$51100-52800$ & $0 ; \quad 0$ & +29 & 9 & 0 & - \\
$52800-54850$ & $0 ; 30$ & -70 & 10 & -0.031 & 0.001 \\
$54850-56040$ & $30 ; 60$ & +19 & 8 & 0 & - \\
$56040-56835$ & $60 ; \quad 0$ & -30 & 10 & 0.067 & 0.043 \\
\hline
\end{tabular}

\subsection{SIMULATED JUMPS OF GPS COORDINATE VARIATIONS.}

The adopted values of the simulated jumps of GPS coordinates are collected in Table 8. A part of jumps differs for the coordinates in East and Up directions. The time interval between jumps is chosen within the range of 2-3 years. In order to improve the determination of breaking epoch, the annual oscillations are excluded from the original and integrated time series (Fig. 10). The residuals of estimated data jumps and changes in trend of GPS station Wettzell in East direction are below $0.3 \mathrm{~mm}$ and $0.13 \mathrm{~mm} / \mathrm{a}$ (Table 9), while in Up direction they are below $0.6 \mathrm{~mm}$ and $0.3 \mathrm{~mm} / \mathrm{a}$ (Table 10).

Table 8 Data and velocity jumps of the models of GPS coordinates variations in East direction (E) and vertical direction (U).

\begin{tabular}{lccc}
\hline \multicolumn{2}{c}{ Time } & Data $[\mathrm{mm}]$ & Change in trend $[\mathrm{mm} / \mathrm{a}]$ \\
\hline 1997.0 & 1999.4 & -0.5 & 0.0 \\
1999.4 & 2002.0 & +0.5 & 0.0 \\
2002.0 & 2004.1 & -1.5 & 0.0 \\
2004.1 & 2006.2 & 0.0 & $+0.5(\mathrm{E})+2(\mathrm{U})$ \\
2006.2 & 2009.0 & $-1.0(\mathrm{E}) 0.0(\mathrm{U})$ & $-0.3(\mathrm{E})-1(\mathrm{U})$ \\
\hline
\end{tabular}



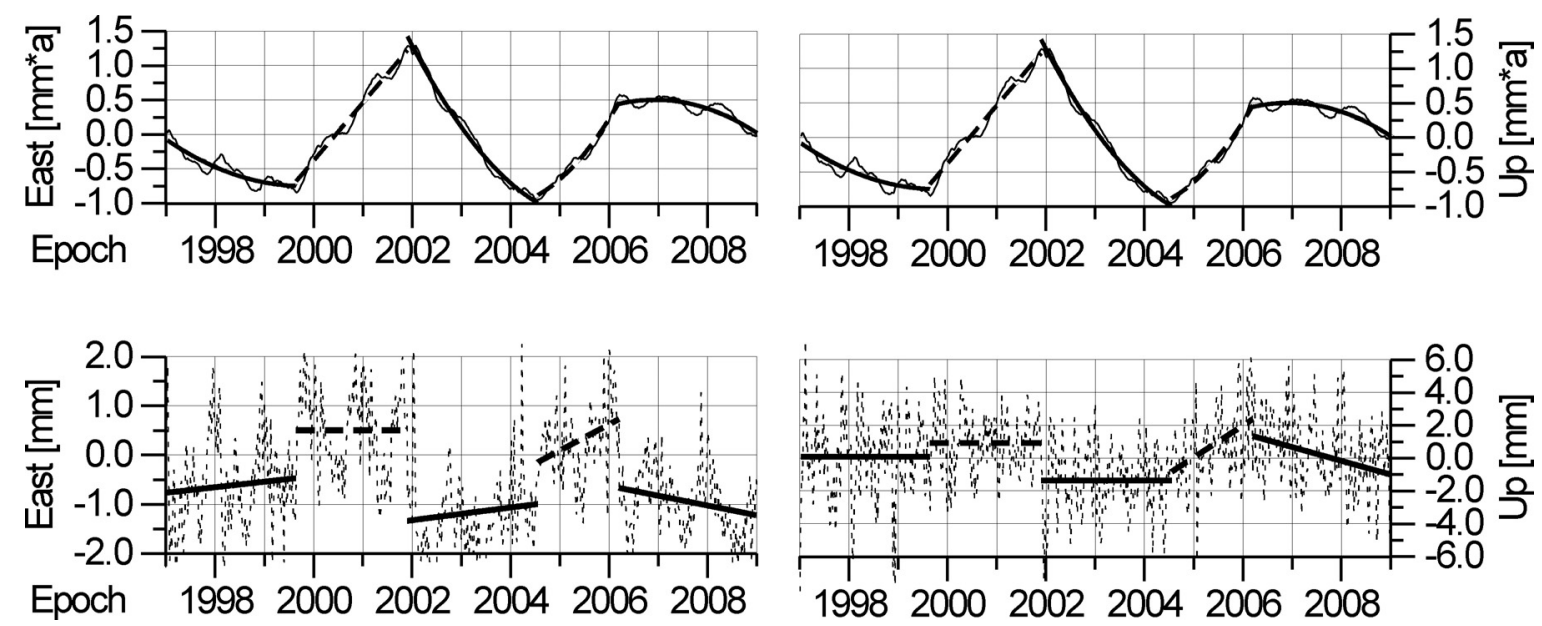

Fig. 10 Integrated time series of GPS Wettzell station coordinate (upper graphs) and determined jumps.

Table 9 Estimated jumps of GPS station Wettzell in East direction.

\begin{tabular}{|c|c|c|c|c|c|}
\hline Time interval & $\begin{array}{c}\text { Errors } \\
\text { [years] }\end{array}$ & $\begin{array}{l}\text { Data j. } \\
{[\mathrm{mm}]}\end{array}$ & $\begin{array}{c}\text { Residuals } \\
\text { [mm] }\end{array}$ & $\begin{array}{c}\text { Trend } \\
{[\mathrm{mm} / \mathrm{a}]}\end{array}$ & $\begin{array}{c}\text { Residuals } \\
{[\mathrm{mm} / \mathrm{a}]}\end{array}$ \\
\hline $1997.00-1999.64$ & $0 ; \quad 0.24$ & -0.63 & 0.13 & 0.11 & 0.11 \\
\hline $1999.64-2001.90$ & 0.24 & 0.46 & 0.04 & 0 & - \\
\hline $2001.90-2004.55$ & 0.10 & -1.22 & 0.28 & 0.13 & 0.13 \\
\hline $2004.55-2006.20$ & 0.45 & 0.26 & 0.26 & 0.59 & 0.09 \\
\hline $2006.20-2009.00$ & 0 & -0.95 & 0.05 & -0.21 & 0.09 \\
\hline
\end{tabular}

Table 10 Estimated jumps of GPS station Wettzell in vertical direction.

\begin{tabular}{clcccc}
\hline Time interval & $\begin{array}{c}\text { Errors } \\
{[\text { years }]}\end{array}$ & $\begin{array}{c}\text { Data j. } \\
{[\mathrm{mm}]}\end{array}$ & $\begin{array}{c}\text { Residuals } \\
{[\mathrm{mm}]}\end{array}$ & $\begin{array}{c}\text { Trend } \\
{[\mathrm{mm} / \mathrm{a}]}\end{array}$ & $\begin{array}{c}\text { Residuals } \\
{[\mathrm{mm} / \mathrm{a}]}\end{array}$ \\
\hline $1997.0-1999.4$ & $0 ; 0$ & +0.1 & 0.6 & 0 & - \\
$1999.4-2001.9$ & $0 ; 0.1$ & +0.9 & 0.4 & 0 & - \\
$2001.9-2004.7$ & $0.1 ; 0.6$ & -1.2 & 0.3 & 0 & - \\
$2004.7-2006.3$ & $0.6 ; 0.1$ & +0.6 & 0.6 & +1.7 & 0.3 \\
$2006.3-2009.0$ & $0.1 ; 0$ & +0.3 & 0.3 & -1.04 & 0.04 \\
\hline
\end{tabular}

\subsection{SIMULATED JUMPS OF CLIMATIC DATA.}

The precipitation and temperature over Balkan Peninsula have rather long time series, so we may choose decadal time interval between the jumps from 35 to 70 years. The model of simulated jumps of climatic data is shown in Table 11. The residuals of data jumps of precipitation over the Balkan Peninsula are between $0.2 \mathrm{~mm}$ and $0.8 \mathrm{~mm}$ with a false jump detection of $0.2 \mathrm{~mm}$, so the sensitivity of the method of impulse detection is above $0.2 \mathrm{~mm}$ and accuracy better than $0.8 \mathrm{~mm}$ (Fig. 11, Table 12). The changes in trend are determined with residuals from $0.02 \mathrm{~mm} / \mathrm{a}$ to $0.07 \mathrm{~mm} / \mathrm{a}$. The data jumps of temperature over the Balkan Peninsula are estimated with errors $0.04 \div 0.2{ }^{\circ} \mathrm{C}$ and changes in trend - with errors $0.002 \div 0.009{ }^{\circ} \mathrm{C} / \mathrm{a}$ (Table 13). These residuals are relatively high due to the decadal time interval between jumps. In the case of time interval between

Table 11 Data and velocity jumps of the models of precipitation and temperature over the Balkan Peninsula.

\begin{tabular}{cccccc}
\hline \multicolumn{2}{c}{ Time } & \multicolumn{2}{c}{ Precipitation } & \multicolumn{2}{c}{ Temperature } \\
& & Data $[\mathrm{mm}]$ & Trend $[\mathrm{mm} / \mathrm{a}]$ & Data $\left[{ }^{\circ} \mathrm{C}\right]$ & Trend $\left[{ }^{\circ} \mathrm{C} / \mathrm{a}\right]$ \\
\hline 1768 & 1800 & -1.0 & -0.1 & -0.1 & -0.06 \\
1800 & 1870 & 0.0 & 0.0 & 0.0 & 0.0 \\
1870 & 1905 & +2.0 & -0.2 & +0.2 & -0.04 \\
1905 & 1940 & -3.0 & +0.3 & -0.3 & +0.02 \\
1940 & 2000 & 0.5 & -0.05 & 0.05 & -0.01 \\
\hline
\end{tabular}



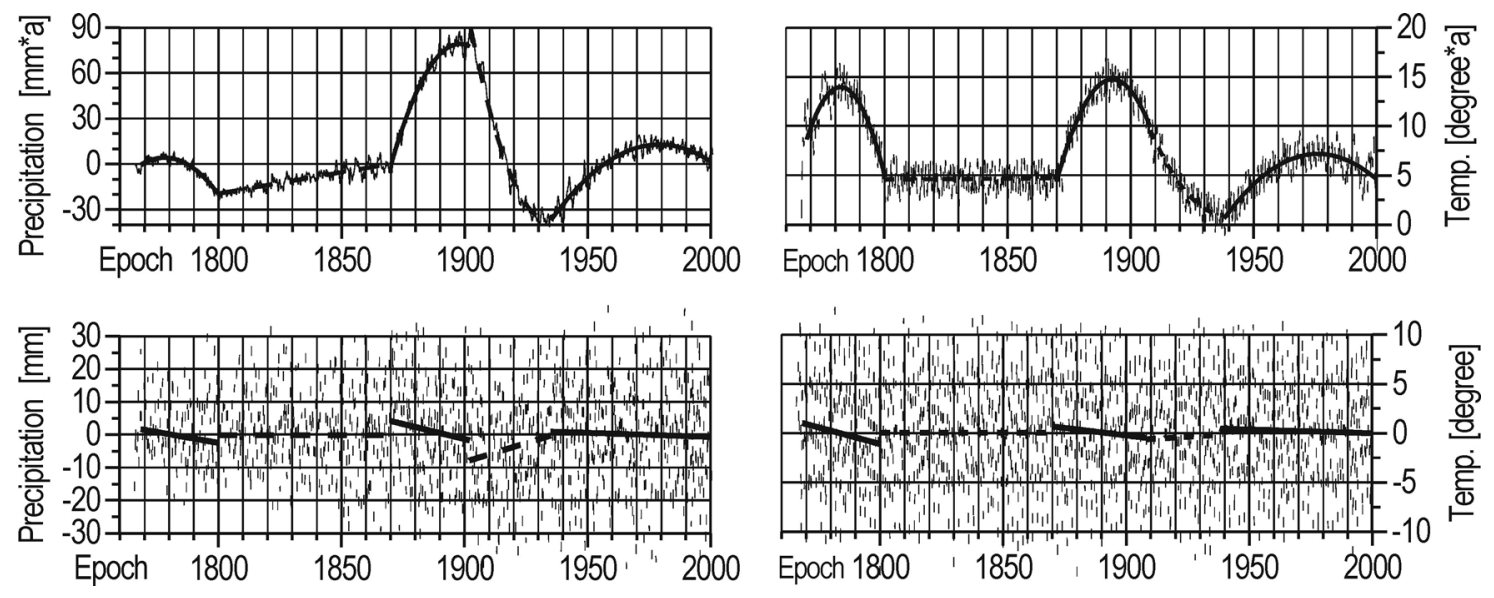

Fig. 11 Integrated time series of precipitation and temperature over the Balkan Peninsula (upper graphs) and determined jumps.

Table 12 Estimated jumps of precipitation over the Balkan Peninsula.

\begin{tabular}{cccccc}
\hline Time interval & $\begin{array}{c}\text { Errors } \\
{[\text { years }]}\end{array}$ & $\begin{array}{c}\text { Data jumps } \\
{[\mathrm{mm}]}\end{array}$ & $\begin{array}{c}\text { Residuals } \\
{[\mathrm{mm}]}\end{array}$ & $\begin{array}{c}\text { Trend } \\
{[\mathrm{mm} / \mathrm{a}]}\end{array}$ & $\begin{array}{c}\text { Residuals } \\
{[\mathrm{mm} / \mathrm{a}]}\end{array}$ \\
\hline $1768-1800$ & $0 ; 0$ & -0.43 & 0.6 & -0.13 & 0.03 \\
$1800-1870$ & $0 ; 0$ & +0.2 & 0.2 & 0 & - \\
$1870-1902$ & $0 ; 3$ & +2.8 & 0.8 & -0.15 & 0.05 \\
$1902-1935$ & $3 ; 5$ & -3.7 & 0.7 & +0.23 & 0.07 \\
$1935-2000$ & $5 ; 0$ & +0.7 & 0.2 & -0.03 & 0.02 \\
\hline
\end{tabular}

Table 13 Estimated jumps of temperature over the Balkan Peninsula.

\begin{tabular}{cccccc}
\hline Time interval & $\begin{array}{c}\text { Errors } \\
{[\text { years }]}\end{array}$ & $\begin{array}{c}\text { Data jumps } \\
{\left[{ }^{\circ} \mathrm{C}\right]}\end{array}$ & $\begin{array}{c}\text { Residuals } \\
{\left[{ }^{\circ} \mathrm{C}\right]}\end{array}$ & $\begin{array}{c}\text { Trend } \\
{\left[{ }^{\circ} \mathrm{C} / \mathrm{a}\right]}\end{array}$ & $\begin{array}{c}\text { Residuals } \\
{\left[{ }^{\circ} \mathrm{C} / \mathrm{a}\right]}\end{array}$ \\
\hline $1768-1800$ & $0 ; 0$ & -0.24 & 0.14 & -0.058 & 0.002 \\
$1800-1870$ & $0 ; 0$ & +0.13 & 0.13 & 0 & - \\
$1870-1908$ & $0 ; 3$ & +0.40 & 0.20 & -0.031 & 0.009 \\
$1908-1938$ & $3 ; 2$ & -0.34 & 0.04 & +0.022 & 0.002 \\
$1938-2000$ & $2 ; 0$ & -0.013 & 0.06 & -0.013 & 0.003 \\
\hline
\end{tabular}

jumps being shorter than 10 years, the expected error of determination of changes in trend is one order higher. The sensitivity of the method of impulse detection in case of temperature data jumps is between the values of false detection of jump $0.13{ }^{\circ} \mathrm{C}$ and maximun residual $0.2^{\circ} \mathrm{C}$.

\section{CONCLUSIONS}

1. The method of detection of data jumps and changes in trend based on the linear and parabolic trends in the integrated time series is highly sensitive to any impulse behavior of the observed variations due to various geophysical processes like earthquakes, tornadoes, hurricanes, geomagnetic jerks or to some systematic deviations of the data composed from different instruments, stations and observers. The method works well with evenly and non-evenly distributed values in time series and it is non sensitive to the large data gaps.

2. The method is remarkably sensitive to very small data jumps, which are usually hidden inside the random noise and high frequency oscillations of the data. The ability of the method to detect small jumps significantly less than the amplitudes of high frequency oscillations and random noise is due to the fact that the integrated amplitude of the high frequency elements is equal almost to zero, while the magnitude of constant or linear parts is increasing linearly with time.

3. The amplitudes of integrated periodic components are reciprocal to their frequencies, so the high-frequency noise results in amplitudes significantly smaller than the original data, while 
the low-frequency signals increase their amplitudes in integrated time series. These properties allow a detection of impulse variations 5-10 times less (in some cases even better) than the level of high-frequency noise.

4. The time series with dominating random noise and outliers contain systematic data jumps with magnitudes smaller than $5 \%$ of the maximal noise level. Preliminary filtration of outliers may reduce the magnitude of the fictive jumps to a half. The trend variations on time scale larger than 5 years are not significantly affected by the data jumps due to random noise and outliers. Also, the trend's value from long period of time is not significantly affected by the systematic jumps, due to average of several data parts with the sign interchange.

5. The sensitivity and accuracy of the method of jump detection depends on the properties of observed data and used time series. In case of polar motion, this method is sensitive to data jump of about 13 mas and provide estimation with accuracy better than 13 mas and sensitive to changes in trend of about 3 mas/a with accuracy better than 3 mas/a. The additional 150 mas pseudo normally distributed random noise decrease the sensitivity and accuracy of data jump by $50 \%$. The data jumps above $10 \mu$ as and changes in trend below $10 \mu \mathrm{as} / \mathrm{a}$ are detectable in celestial pole offset with accuracy better than $10 \mu$ as and $16 \mu$ as/a. The jumps of GPS coordinate are detectable above $0.3 \mathrm{~mm}$ with accuracy better than $0.3 \mathrm{~mm}$ in horizontal components and above $0.6 \mathrm{~mm}$ in vertical component with accuracy better than $0.6 \mathrm{~mm}$. The corresponding values of changes in trend are $0.13 \mathrm{~mm} / \mathrm{a}$ in horizontal plane and $0.3 \mathrm{~mm} / \mathrm{a}$ in vertical direction. The jumps in climate data are detectable above the level of $0.2 \mathrm{~mm}$ with accuracy better than $0.8 \mathrm{~mm}$ in case of precipitation and above $0.2{ }^{\circ} \mathrm{C}$ in case of temperature with accuracy better than $0.2^{\circ} \mathrm{C}$. The detectable levels of changes in trend of precipitation and temperature are below $0.1 \mathrm{~mm}$ and $0.01{ }^{\circ} \mathrm{C}$ with accuracy better than $0.07 \mathrm{~mm}$ and $0.009{ }^{\circ} \mathrm{C}$. The jump epochs are determined with errors up to half a year for short decadal time series and below 3 years for time series longer than two centuries. The inaccurate determination of jump epochs may decrease the sensitivity of the method of jump detection and increase the errors of estimated jumps.

\section{ACKNOWLEDGEMENTS}

This research was financially supported by the grant No. 13-15943S "Geophysical excitations in the motion of Earth's axis of rotation", awarded by the Grant Agency of the Czech Republic.

\section{REFERENCES}

Casty, C., Handorf, D. and Sempf, M.: 2005, Combined climate winter regimes over the North Atlantic/European sector 1766-2000. Geophysical Research Letters, 32, 1. DOI: 10.1029/2005GL022431

Casty, C., Raible, C.C., Stocker, T.F., Luterbacher, J. and Wanner, H.: 2007, A European pattern climatology 1766-2000. Climate Dynamics, 29, 7, 791-805. DOI: $10.1007 / \mathrm{s} 00382-007-0257-6$.

Chapanov, Ya., Ron, C. and Vondrák, J.: 2008a, Estimation of the short-term zonal tides from UT1 observations. Proc. "Journées 2007 Systemes de référence spatiotemporels", N. Capitaine (ed.), Observatoire de Paris, 208-209.

Chapanov, Ya. and Gambis, D.: 2008b, Influence of AAM and OAM on the Universal time variations AIP. Conf. Proc., vol. 1043 "Exploring the Solar system and the Universe", Melville, New York, 218-219.

Chapanov, Ya. and Pachalieva, R.: 2013, Data jumps determination by a high sensitive method of impulse detection. Proc. Int. Symp. on "Modern technologies, education and professional practice in geodesy and related fields", Sofia, 07 - 08 November 2013.

Chapanov, Ya., Vondrák, J. Ron, C and Pachalieva, R.: 2014, Natural and systematic polar motion jumps. Proc. Journées 2013 "Systèmes de référence spatiotemporels", N. Capitaine (ed.), Paris, 193-196.

Forsythe, G. E., Malcolm, M. A. and Moler, C. B.: 1977, Computer Methods for Mathematical Computations, Prentice-Hall.

Gambis, D., Salstein, D. and Chapanov, Ya.: 2011, Some systematic errors in AAM and OAM data. Proc. "Journées 2011 Systèmes de référence spatiotemporels", H. Schuh, S. Böhm, T. Nilsson and N. Capitaine (eds.), Paris, 162-163.

Rodionov, S.N.: 2005, A brief overview of the regime shift detection methods. In: V. Velikova,"N. Chipev (eds.), UNESCO-ROSTE/BAS Workshop on Regime Shifts, Varna, 17-24.

Ron, C., Vondrák, J. and Chapanov, Ya.: 2014, Free core nutation - possible causes of changes of its phase and amplitude. Proc. "Journées 2013 Systèmes de référence spatio-temporels", N. Capitaine (ed.), Paris, 164-167. 